\title{
Fair-weather atmospheric electricity study at Maitri (Antarctica)
}

\author{
Devendraa Siingh ${ }^{1}$, R. P. Singh ${ }^{2}$, V. Gopalakrishnan ${ }^{1}$, C. Selvaraj ${ }^{3}$, and C. Panneerselvam ${ }^{3}$ \\ ${ }_{1}^{1}$ Indian Institute of Tropical Meteorology, Pune 411 008, India \\ ${ }^{2}$ Department of Physics, Banaras Hindu University, Varanasi 22 1005, India \\ ${ }^{3}$ Equatorial Geophysical Research Laboratory, Indian Institute of Geomagnetism, Krishnapuram, Tirunelveli, 627011 , India
}

(Received February 25, 2013; Revised August 30, 2013; Accepted September 17, 2013; Online published December 6, 2013)

\begin{abstract}
Results of near-surface measurements of atmospheric electric field and meteorological parameters at the Indian Antarctic station, Maitri, during 12 fair-weather days of January and February, 2005, are presented. Data are analyzed to study the diurnal variation of the electric field and its departure, if any, from the global electric fields. Fair-weather days are classified into two groups depending upon the average of the hourly surface temperature. Group one, when the average of the hourly surface temperature is mostly above the freezing point, and group two, when the same is below the freezing point. The role of different ion sizes on the Maxwell current density and the air-Earth current density for the two groups are quite different under different conditions. To study the effect of ions on the atmospheric electric fields, ions are grouped as small ions, intermediate ions and large ions. We find that the small and the large ions largely influence the air-Earth current density with a correlation coefficient higher than $70 \%$. The intermediate ions have a negative correlation in the case of group one fair-weather days, whereas for group two days no correlation is found. The diurnal variations of the Maxwell current density and the electric field show a peak between 1800 UT and 2000 UT and the nature of the variation can be attributed to the variation in worldwide thunderstorm activity. The correlation coefficient between the measured electric field and the electric field from the Carnegie curve is 0.93 with a $<0.0001$ significance level. Thus, the observed electric field at Maitri represents the global electric field. The results show that a wind velocity of less than $10 \mathrm{~m} / \mathrm{s}$ and a surface temperature of lower than $+7^{\circ} \mathrm{C}$ have almost no impact on the electric field and Maxwell current density. Key words: Antarctica, electric field, Maxwell current density, global electric circuit, surface conductivity, atmospheric ions, potential gradient, air-Earth current density.
\end{abstract}

\section{Introduction}

It is known that a weak current of about $1-6 \mathrm{pA} / \mathrm{m}^{2}$ flows between the ionosphere and the Earth's surface, which is maintained by lower atmospheric electric generators (mostly thunderstorms and strongly electrified clouds occurring around the globe) and upper atmospheric electric generators (which are in the polar caps). Thunderstorms generate an upward current of $\sim 1000$ A and maintain the vertical potential gradient $(\sim 250 \mathrm{kV})$ between the ionosphere and the ground (Alderman and Williams, 1996; Burns et al., 1995; Rycroft et al., 2000; Singh et al., 2004; Siingh et al., 2005a, 2007a, 2008). The ionospheric potential shows $\pm 40 \mathrm{kV}$ of diurnal variation in universal time; because, as the Earth rotates, thunderstorm activity maximizes successively in the late afternoon-evening local time over the non-uniformly distributed land masses around the globe. The global component of the variation of the atmospheric electric field is obtained by integrating over the globe and it follows universal time. The effect is different for variation originating by global and local processes (Williams and Heckman, 1993; Williams, 1994; Sheftel et al., 1994; Rycroft et al., 2000; Troshichev et al., 2004). The

Copyright (C) The Society of Geomagnetism and Earth, Planetary and Space Sciences (SGEPSS); The Seismological Society of Japan; The Volcanological Society of Japan; The Geodetic Society of Japan; The Japanese Society for Planetary Sciences; TERRAPUB.

doi:10.5047/eps.2013.09.011 local component of a variation is governed by local meteorological processes and follows local time.

The influence of solar activity on the atmospheric electric field differs between mid-latitudes and high latitudes / Polar Regions. The measurement of fields at mid-latitudes contains variations due to local effects, in addition to global components. A local diurnal variation does not exist in the Polar Regions (Israel, 1973) and hence the measurement of field in these regions could represent the global variation. However, drifting snow and the polar cap potential may affect atmospheric field parameters. The solar wind interaction with the Earth's magnetic field generates a cross polar cap potential difference in the range 30-60 kV (Papitashvili et al., 1999; Rycroft et al., 2000), and which, during enhanced solar activity, may exceed 100 $\mathrm{kV}$ and expand equatorwards (Boyle et al., 1997; Rycroft et al., 2000; Siingh et al., 2011a; Williams and Mareev, 2013). This part of the field corresponds to a horizontal potential and may affect measured field parameters. The Maitri station is outside the auroral oval during magnetically quiet times and is encompassed by the auroral oval under magnetically disturbed conditions. During a sunspot maximum period, one would expect more magnetic storms that may produce large day-to-day variations in the electric fields and the Maxwell currents. Based on measurements at the Maitri station, Panneerselvam et al. (2007a) concluded that during magnetically quiet and moderate conditions, the 
variations of measured atmospheric electric field parameters are similar to the Carnegie curve. However, the diurnal pattern during magnetically disturbed conditions differs from the Carnegie curve due to contributions from the ionosphere/magnetosphere. The solar activity was at its deep minimum during 2005 with unusually long periods without sunspots and a relatively very weak dipolar field strength (Nandy et al., 2011). As a result, the polar cap potential would be relatively small and its effect outside the auroral oval is expected to be small, which is likely to be further reduced during the averaging of data for the fair-weather days. In the present study, the effect of the polar cap potential on the atmospheric electrical field parameters is considered to be small and is therefore ignored.

The presence of drifting snow in the atmosphere is governed by wind velocity. The larger the wind velocity, the larger will be the number of particles. Minamoto and Kadokura (2011) have analyzed atmospheric electric field data at the Syowa station, Antarctica, and defined fairweather days to be those with a wind speed of less than 6 $\mathrm{m} / \mathrm{s}$ and a cloud coverage level of less than $10 \%$. However, based on measurements at Maitri, Deshpande and Kamra (2001) considered fair-weather days to be those when the wind speed is less than $10 \mathrm{~m} / \mathrm{s}$. They showed that the percent deviation in the electric field lies within $\pm 50 \%$ for wind speed lower than $10 \mathrm{~m} / \mathrm{s}$ and all the other criteria of fair-weather are satisfied. This factor remains mostly positive and may exceed $+50 \%$ when the wind speed exceeds $10 \mathrm{~m} / \mathrm{s}$. Based on these facts, we have considered a wind speed of $\leq 10 \mathrm{~m} / \mathrm{s}$ as the criteria for fair-weather days at Maitri.

Ground-based measurements are often contaminated by the presence of ground radioactivity, atmospheric aerosols, turbulence and convection currents. Even columnar resistance, electrical conductivity, seasonal variations, ionospheric horizontal fields, and active thunderstorms in the area may influence the universal electric fields at a regional level (Takagi, 1977). However, measurements made at clean places such as over oceans (Mauchly, 1923; Ruttenberg and Holzer, 1955; Morita, 1971; Kamra et al., 1994), over high mountains (Cobb, 1968; Reiter, 1992), over exchange layers (Anderson, 1967; Markson, 1977), in the polar regions (Kasemir, 1972; Park, 1976; Cobb, 1977, Burns et al., 1995; Bering et al., 1998; Fuellekrug et al., 1999) and in the Antarctic (Despande and Kamra, 2001; Panneerselvam et al., 2007a; Minamoto and Kadokura, 2011; Jeeva et al., 2011) have been used to study the global variation of atmospheric fields and to verify the global circuit concept postulated by Wilson (1925) and to confirm the unitary diurnal variation in the electric field. Alderman and Williams (1996) studied the air-Earth current density at Mauna Loa, Hawaii, which is free of pollution, and observed a single peak at 1900 UT. Apart from the global universal time variations, land stations also exhibit local time variations typical of their locations.

The global electric field model (Wilson, 1920) includes charging current sources in thunderstorms and discharging current at all other sites. The experimental support for this model is that the universal daily variation of the electric field measured over the ocean regions (Carnegie curve) is consistent with the diurnal variation of thunderstorm activity integrated over the globe (Alderman and Williams, 1996; Bering et al., 1998; Siingh et al., 2005a, 2007a). Observations by Mauchly (1923) over open oceans support the hypothesis proposed by Wilson that thunderstorms feed the global electric circuit. These observations are repeated at poles and at clean places to verify these results as they are free of any local effects that may mask the global variation. The Antarctic region is one of the best places to verify the global electric circuit (GEC) as there is little human activity and the region is free from any anthropogenic sources of pollution. The Antarctic plateau supports a desert-like continent during the observation period as the winds are light, mostly flowing in a nearly constant direction and the atmosphere is relatively free of turbulent and convective motions (Byrne et al., 1993; Deshpande and Kamra, 2001).

In this paper, we report the measurements of various atmospheric electric parameters made at the Maitri station (lat. $70^{\circ} 45^{\prime} 52^{\prime \prime} \mathrm{S}$, long. $11^{\circ} 44^{\prime} 03^{\prime \prime} \mathrm{E} ; 130 \mathrm{~m}$ above mean sea level) situated on the Antarctic plateau, during JanuaryFebruary, 2005. Our objective is to study the diurnal variation of fair-weather electric fields at a relatively pollutionfree place, and to find out the extent to which the measured field represents the universal Carnegie fields. Section 2 describes briefly the instruments used, the measurement site and the weather conditions at Maitri. Section 3 presents the data selection. Section 4.1 discusses the diurnal variation of the electrical parameters. The role of ions of different sizes on atmospheric electrical parameters is presented in Section 4.2. Section 5 discusses the dependence of atmospheric electrical parameters on the surface temperature and wind velocity. The diurnal variation of conductivity is discussed in Section 6. Section 7 compares the measured electric fields with the earlier measurements of fair-weather fields at other locations. Finally, the results are summarized in Section 8.

\section{Instruments, Measurement Site and Weather}

The measurements of atmospheric electrical parameters (potential gradient, Maxwell current, air-Earth current density and different categories of ions) during the 24th Indian Antarctic Expedition were made at the Indian Antarctic station Maitri, which is located in the Schirmacher Oasis of Dronning Maud (also known as Queen Maud) Land, East Antarctica, and is about $90 \mathrm{~km}$ away from the coast line in the summer (January to February, 2005). The generators, gas plant, incinerator and living modules are about $300 \mathrm{~m}$ away in a southwest direction from the measurement site. Any pollutants released from these sources had very little chance of reaching the site of measurements due to prevailing south-easterly or south-southwesterly winds. The positions of Maitri, and some other stations close to Maitri, on the Antarctic continent are shown in Fig. 1. The observatory (Kamet hut) at Maitri station is the location of the atmospheric electric field measurement. There are steep cliffs, frozen lakes and an ice-shelf extending to about 90 $\mathrm{km}$ in the summer on the northern side of the Maitri station. On the southern side, polar ice occurs with an ice-rock interface. However, because the cliffs are far away and not very high, oceanic air is not obstructed from reaching the 


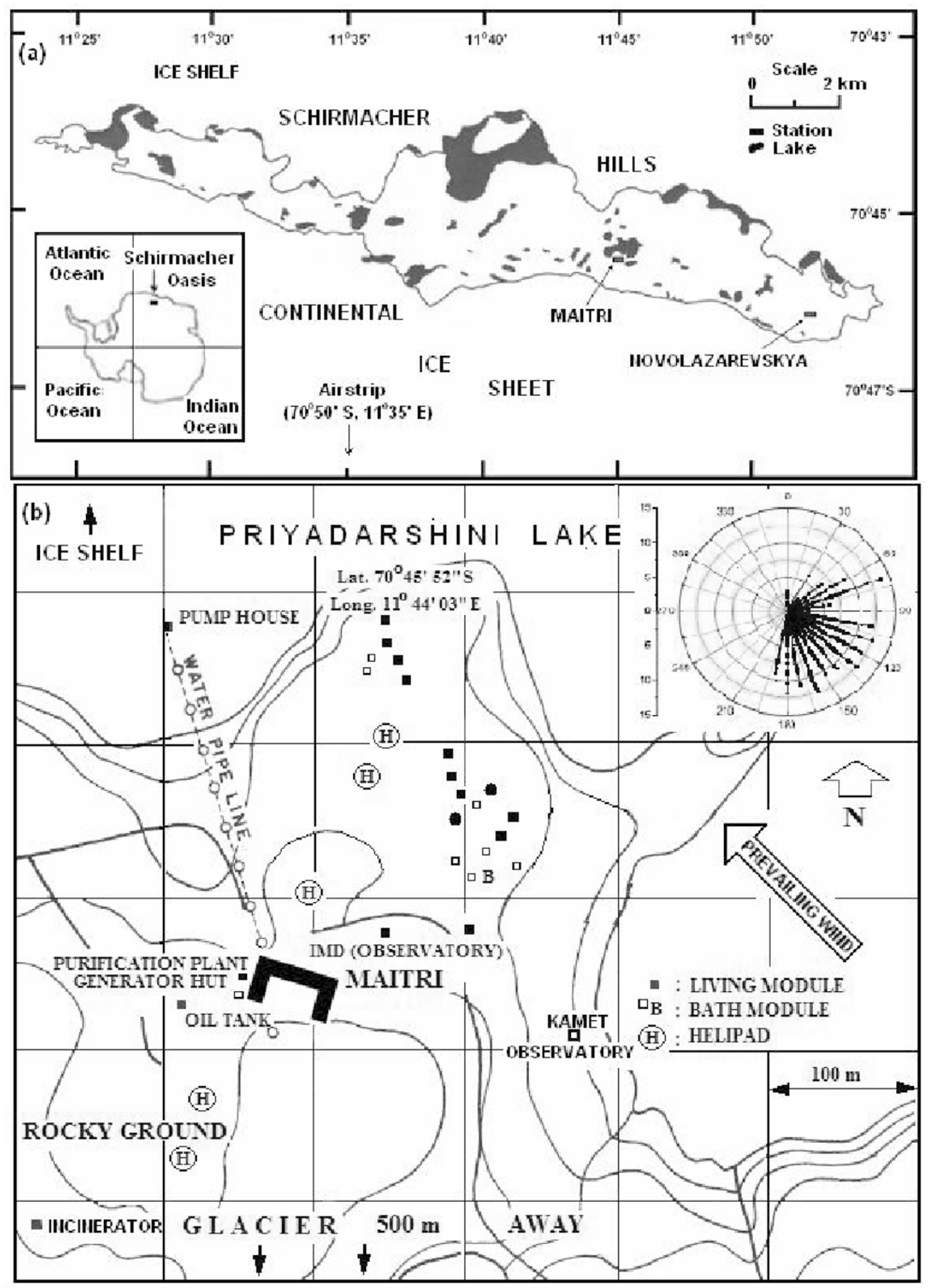

Fig. 1. (a) The map of Antarctica showing the location of the Maitri station and some other stations close to Maitri on the Antarctic continent. (b) location of instruments (Kamet observatory) at the Maitri and the wind-rose showing the magnitudes and directions of wind speed during the period from January to February, 2005 (Siingh et al., 2007b; Pant et al., 2010). Kamet observatory showed in map by arrow in Fig. 1(b).

station. Details of the Maitri site can be found elsewhere (Siingh et al., 2007b, 2011b, 2012; Pant et al., 2010).

The atmospheric electric field is measured with a vertical alternating current (AC) field mill which is made out of nonmagnetic stainless steel to reduce the contact potential (Willett and Bailey, 1983). The details of the AC field mill has been discussed by Deshpande and Kamra (2001). The sensor plates and rotor used in the field mill are of 8.5 $\mathrm{cm}$ diameter. The shaft of the AC motor $(220 \mathrm{~V}, 50 \mathrm{~Hz}$, $1500 \mathrm{rpm}$ ) is grounded with a carbon brush. The weak signal is amplified with an amplifier circuit which is fitted in- side the field mill. The time constant of the field mill is $1 \mathrm{~s}$. For the electronic circuit, military grade components are used which maintain their characteristics even in subzero temperatures. The amplified signals are fed through teflon-insulated coaxial cables to a PC-based data acquisition system, which is kept inside a hut $6 \mathrm{~m}$ in height and $35 \mathrm{~m}$ away from the the field mill. The sampling rate for each instrument is 1 per second but the data are stored on 1 min-average and 1-hour average modes during the entire measurements. The cleaning of insulators and other maintenance of field mill was undertaken daily. The zero shifts 


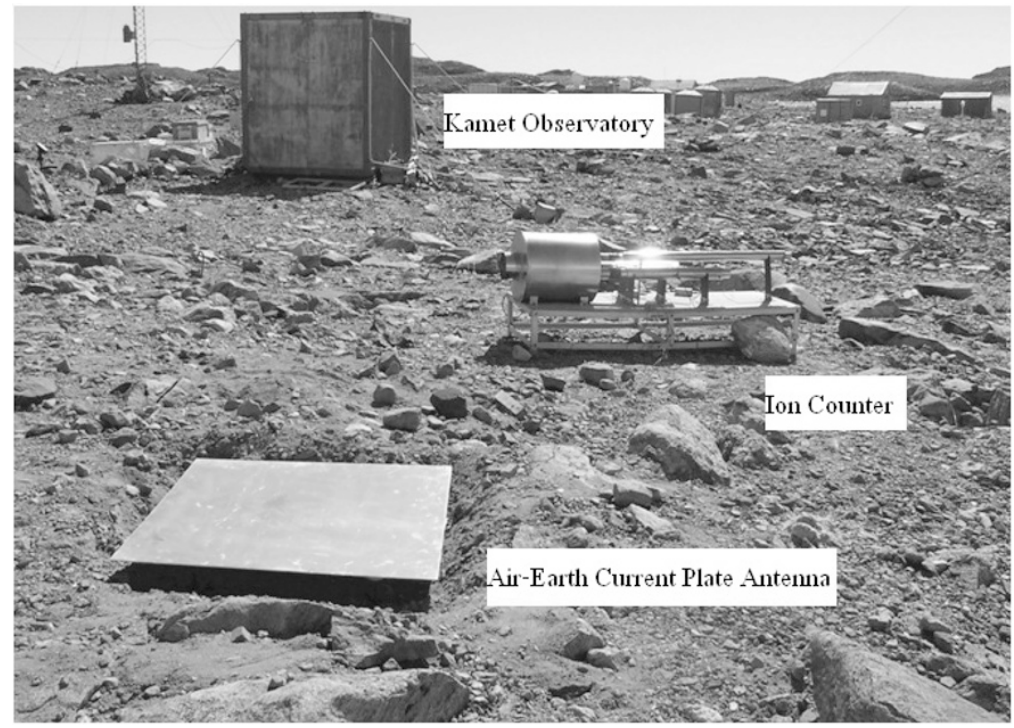

Fig. 2. The ion counter and the air-Earth current plate antenna installed at the Maitri station. The Kamet hut (observatory) is also shown.

Table 1. Dimensions and other parameters of three condensers of the ion-counter.

\begin{tabular}{llll}
\hline Dimensions/constants & Small-ion Condenser & Intermediate-ion Condenser & Large-ion Condenser \\
\hline Length of the outer electrode $(\mathrm{m})$ & 0.4 & 0.8 & 1.2 \\
Length of the inner electrode $(\mathrm{m})$ & 0.2 & 0.5 & 1.0 \\
Diameter of the outer electrode $(\mathrm{m})$ & 0.098 & 0.06 & 0.038 \\
Diameter of the inner electrode (m) & 0.076 & 0.037 & .022 \\
Potential applied (V) & 15 & 100 & 600 \\
Critical mobility $\left(\mathrm{m}^{2} \mathrm{~V}^{-1} \mathrm{~s}^{-1}\right)$ & $0.766 \times 10^{-4}$ & $1.2 \times 10^{-6}$ & $0.97 \times 10^{-8}$ \\
Flow rate $\left(\mathrm{s} \mathrm{s}^{-1}\right)$ & 8.6 & 1.8 & 0.29 \\
\hline
\end{tabular}

were checked every 3 hours and, if found to be appreciable, were corrected.

A long wire of length $41.5 \mathrm{~m}$ and $3 \mathrm{~mm}$ in diameter kept horizontal (stretched parallel) at a height of $2 \mathrm{~m}$ from the Earth's surface is used to measure the Maxwell current. The wire is mechanically supported by masts, using teflon rods at their ends for insulation from the supporting masts. The input signal is fed through the electrometer (model AD-549; military grade). A unit gain operational amplifier (LM 308) amplifies the electrometer output signal, and the amplified signal passes through the shielded coaxial cable and is fed to a PC-based data logger. The data are recorded at a sampling interval of one minute. Details concerning measurement and antenna information have been discussed by Panneerselvam et al. (2003, 2007a, b). The Maxwell current consists of a field-dependent current, convection current, lightning current and displacement current (Krider and Musser, 1982; Siingh et al., 2008). In the absence of lightning discharges, only field-dependent and convection current components exist, which vary rather slowly. When the electric field is zero, the field-dependent component becomes zero. The convection current is produced by the mechanical transport of net space charge by air motion/precipitation.

The concentrations of the small, intermediate, and large ions were measured with an ion counter (Fig. 2), which consists of three Gerdien condensers used for simultaneous measurements of concentrations of small (mobility range $>0.77 \times 10^{-4} \mathrm{~m}^{2} \mathrm{~V}^{-1} \mathrm{~s}^{-1}$; diameter $<1.45 \mathrm{~nm}$ ), interme- diate (mobility range $1.21 \times 10^{-6}-0.77 \times 10^{-4} \mathrm{~m}^{2} \mathrm{~V}^{-1} \mathrm{~s}^{-1}$; diameter range $1.45-12.68 \mathrm{~nm}$ ) and large (mobility range $0.97 \times 10^{-8}-1.21 \times 10^{-6} \mathrm{~m}^{2} \mathrm{~V}^{-1} \mathrm{~s}^{-1}$; diameter range $12.68-$ $130 \mathrm{~nm}$ ) ions. The other features of the ion counter are discussed by Siingh et al. (2005b, 2007b). Dimensions and other technical parameters of the ion counter are given in Table 1.

The air-Earth current is measured with a $1-\mathrm{m}^{2}$ flat plate antenna kept flush with the ground shown in Fig. 2. The inputs from the three condensers of the ion counter and the air-Earth current plate are amplified with separate amplifiers placed close to the sensors and then fed through the coaxial cables to a data logger placed in a nearby hut. The air-Earth current is the total vertical current flowing to the plate and may contain contributions from the turbulent current and displacement current. In fair-weather days, overhead thunderstorm/charged cloud activities are almost absent and hence the displacement current contribution may be almost zero. The contribution from turbulence during fair-weather conditions is negligibly small and the measured vertical current is considered to be the air-Earth current (Panneerselvam et al., 2007a; Siingh et al., 2007b).

The measurements of ambient temperature, pressure, wind speed and direction were made at $5 \mathrm{~m}$ above ground level and the cloud amount was observed visually every hour. In general, meteorological parameters such as the atmospheric temperature and the pressure vary from $-10^{\circ} \mathrm{C}$ to $+8^{\circ} \mathrm{C}$ and $942 \mathrm{hPa}$ to $982 \mathrm{hPa}$, respectively, at Maitri 


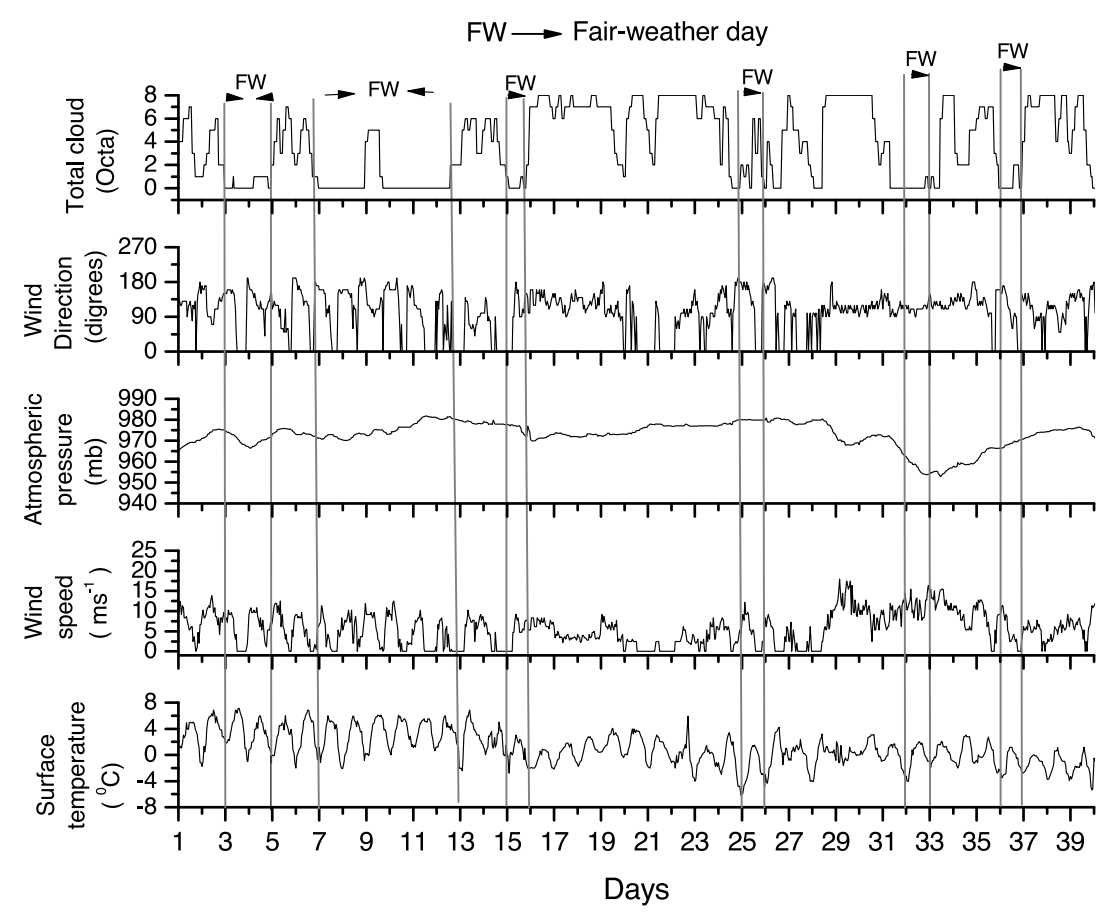

Fig. 3. The variation of the meteorological parameters measured at Maitri from January-February, 2005. Fair-weather days (FW) are marked by vertical lines.

in the months of January and February. Occasionally, the atmospheric pressure drops down to below $942 \mathrm{hPa}$, when a cyclonic storm approaches. The cloud conditions over Maitri are variable but when a cyclonic storm passes through the Maitri station the sky is completely overcast. The surface winds are dominantly south-westerly and bring continental air to Maitri which may contain snow particles if the wind velocity is large. A summary of the meteorological parameters recorded at Maitri is presented in Fig. 3. The cloud coverage varied from 0 to 8 octa, where 8 octa represents a completely overcast condition. The wind direction varied between 0 degrees and 180 degrees and the wind speed varied between 0 and $20 \mathrm{~m} / \mathrm{s}$. The surface temperature varied between $-8^{\circ} \mathrm{C}$ and $8^{\circ} \mathrm{C}$. After the occurrence of a blizzard on 28-29 January, 2005, with heavy snowfall, the whole station was covered with snow, but this melted and left the ground bare by 31 January, 2005. Observations were resumed on the 30 January, 2005, after cleaning the instruments.

\section{Data Selection}

The atmospheric electric field parameters near the Earth's surface are disturbed by the local weather. Therefore, it becomes almost essential to identify and exclude data contaminated by local effects or connected with some large-scale systems. During the data selection process, we could identify 12 fair-weather days within two months, i.e. January and February, 2005. These days were January 3, 4, 7, 8, 9, 10, 11, 12, 15, 25, and February 1, 5. Days are considered to be fair-weather days when there is no rain or snowfall, the wind speed is moderate (less than $10 \mathrm{~m} / \mathrm{s}$ ), low level clouds are absent, and high level clouds are less than 3 octa (Deshpande and Kamra, 2001; Panneerselvam et al., 2007a). On some of the selected days, the wind speed exceeded $10 \mathrm{~m} / \mathrm{s}$ for a very brief period ( $\sim$ an hour) but the measured electric field parameters were found to be within the considered normal range. The air-Earth current measurement could be affected by the blowing space charges present in this lofted dust. However, such days have been included in the fairweather days. We consider the convention that on the fairweather days the electric field pointing downward is negative (i.e. the potential gradient in fair-weather days is positive).

Careful analysis of the data showed a peculiar feature that all the measured parameters had relatively higher values during the last three fair-weather days (January 25, February 1,5$)$. When the average of the hourly surface temperature was considered, it was found to be mostly above the freezing point (zero degrees centigrade) for fair-weather days before January 15 and below the freezing point after January 15. Accordingly we grouped the data into two groups: group one contains data for the fair-weather days from January 3 to January 15 and group two contains data for the days January 25, February 1 and 5. Even though, there are only three days data in group two, we have performed the analysis because the diurnal variations on each day are similar. As the data in group two are quite small, detailed studies have not been carried out. The analysis is made just to compare and validate the results of group one, and no major conclusions could be derived based on the group two data.

\section{Fair-weather Atmospheric Electrical Parame- ters}

\subsection{Diurnal variation}

The diurnal variations of hourly averaged values of the atmospheric electric field parameters, such as the Maxwell current density, the potential gradients, air-Earth current 
(a)
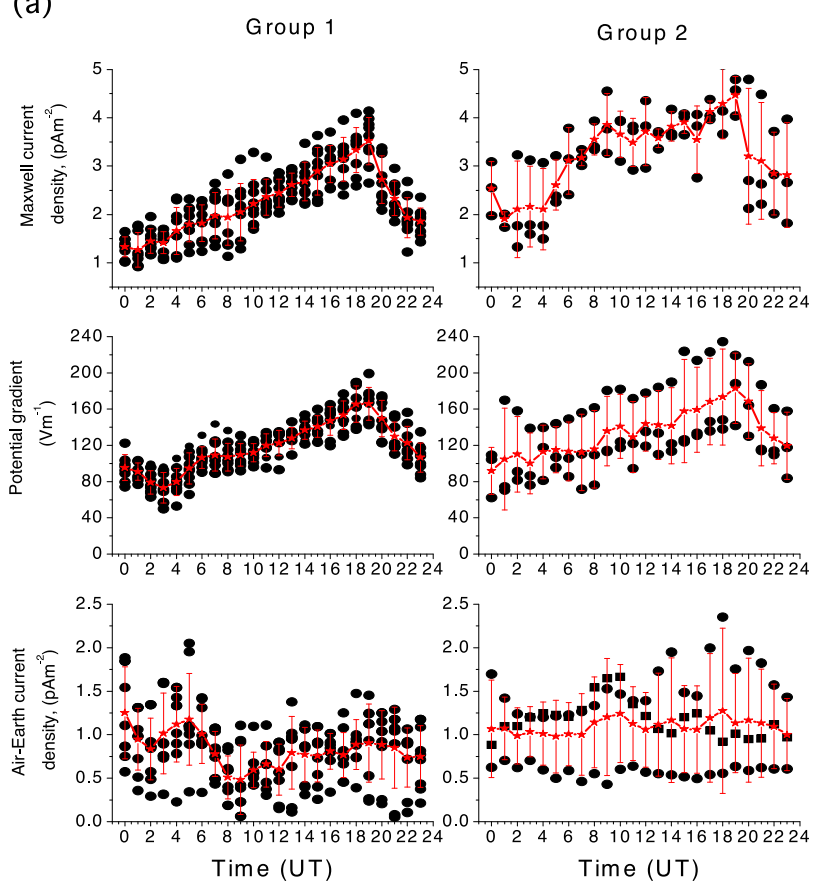

(b)
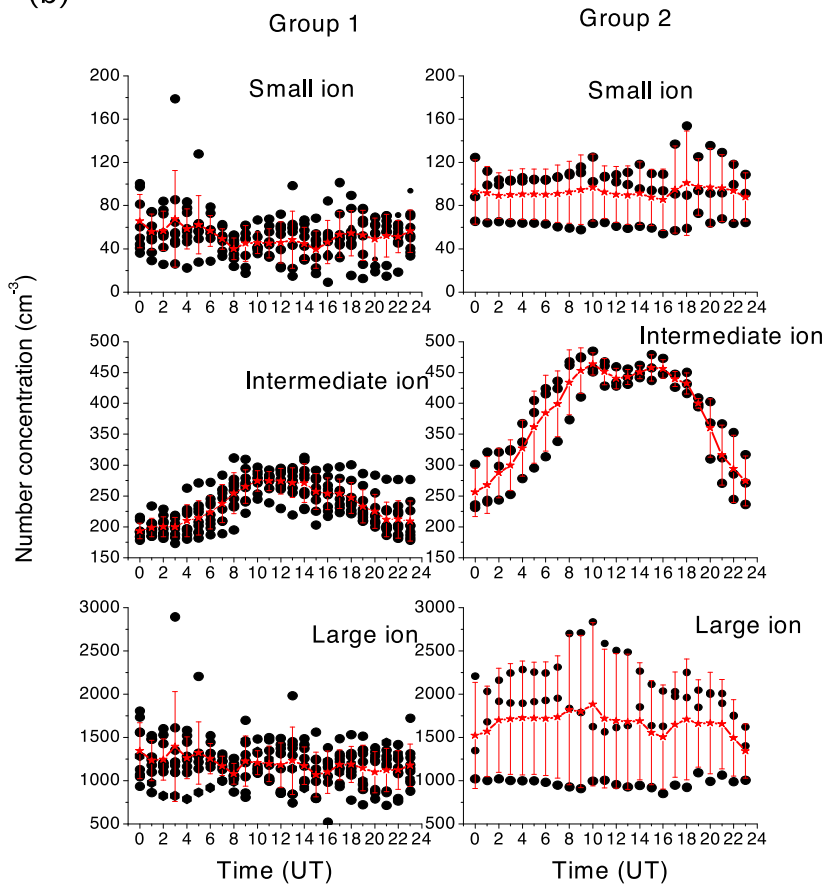

Fig. 4. (a) The diurnal variations of the scattered and the averaged values (red color) of the observed Maxwell current density, the potential gradient, and the air-Earth current density at Maitri for group one and group two days. (b) The same as Fig. 4(a) but for the small ion (mobility $>0.77$ $\mathrm{cm}^{2} \mathrm{~V}^{-1} \mathrm{~s}^{-1}$; diameter $<1.45 \mathrm{~nm}$ ); intermediate ion (mobility $1.21 \times 10^{-2}-0.77 \mathrm{~cm}^{2} \mathrm{~V}^{-1} \mathrm{~s}^{-1}$; diameter $1.45-12.68 \mathrm{~nm}$ ) and large ion (mobility $0.97 \times 10^{-4}-1.21 \times 10^{-2} \mathrm{~cm}^{2} \mathrm{~V}^{-1} \mathrm{~s}^{-1}$; diameter $\left.12.68-130 \mathrm{~nm}\right)$.

density and ion concentrations (small ions, diameter $<1.45$ $\mathrm{nm}$; intermediate ions, diameter range $1.45-12.68 \mathrm{~nm}$; large ions, diameter range $12.68-130 \mathrm{~nm}$ ) for groups one and two, are shown in Fig. 4(a, b). The data for all nine days of group one and the three days of group two are averaged and the diurnal variations are plotted. The day-to-day variation in the Maxwell current density follows the variations in the potential gradient, whereas the variations in the air-Earth current density and the concentrations of the small and large ions are almost similar. The variation in the intermediateion concentration does not follow either the air-Earth current density or the potential gradient. This trend is reflected in the diurnal variation shown in Fig. 4(a, b). The diurnal variations of the potential gradient and the Maxwell current density, in both the groups, show a maxima around 1800-1900 hrs. However, no such peaks are observed in the air-Earth current density and the small- and large-ion concentrations. A small peak in the air-Earth current density around $0500 \mathrm{UT}$ and a small dip in the potential gradient around 0300 UT are observed in the group one data, but the same are not observed in the data of group two. The small- and large-ion concentrations in both groups do not show any diurnal variations. However, from Fig. 4(b), one finds that the ions in the intermediate range show a broad and flat peak between 1000 and 1400 UT for group one, and between 0900 and 1600 UT for group two. The concentrations in group two are much larger as compared with those of group one. In fact, even the concentrations of the small and the large ions in group two are larger than those of group one. The broad peak in the concentration of the intermediate ions around mid-day hours at 0900-1600 UT may be due to the formation of new particles by a photo- oxidation process (Covert et al., 1996; Ito, 1985; Kamra et al., 2009). Davison et al. (1996) and O'Dowd et al. (1997) showed that the rate of new particle formation is strengthened by higher emissions of dimethyl sulphide in the ice melt region around the continent of Antarctica. The photooxidation process is effective in a clean environment with a low aerosol surface area and plenty of available solar radiation. Around mid-day, the maximum solar radiation is available and this may explain the diurnal variation of the intermediate-ion concentrations. On the group two days, the temperature is relatively low $\left(-7^{\circ} \mathrm{C}\right.$ to $\left.3^{\circ} \mathrm{C}\right)$ as compared with group one days $\left(-3^{\circ} \mathrm{C}\right.$ to $\left.8^{\circ} \mathrm{C}\right)$ and, therefore, it is expected that there would be a relatively lower concentration of aerosols on group two days, which may further enhance the production rate of new particles.

Comparing Figs. 4(a) and 4(b), it is observed that the air-Earth current density follows a superimposed variation of the small and the large ions; the variation of the intermediate-ion concentration is independent, and seems to follow the variation of the surface air temperature in both groups. This also indicates that the sources of intermediate ions may be different from that of the small and large ions. The small dip around $0300 \mathrm{UT}$ in the potential gradient of group one decreases when data are averaged for all 12 fair-weather days and the potential gradient and the Maxwell current density show a single maxima at 1800 $1900 \mathrm{hrs}$ and a minima at $0200 \mathrm{hrs}$. Burns et al. (1995) reported a peak in the electric field at Davis, Antarctica, between 1900 UT and 2200 UT. The diurnal variation of the potential gradient and the Maxwell current is attributed to the diurnal variation in the global thunderstorm activity. Panneerselvam et al. (2007a) measured the potential gra- 


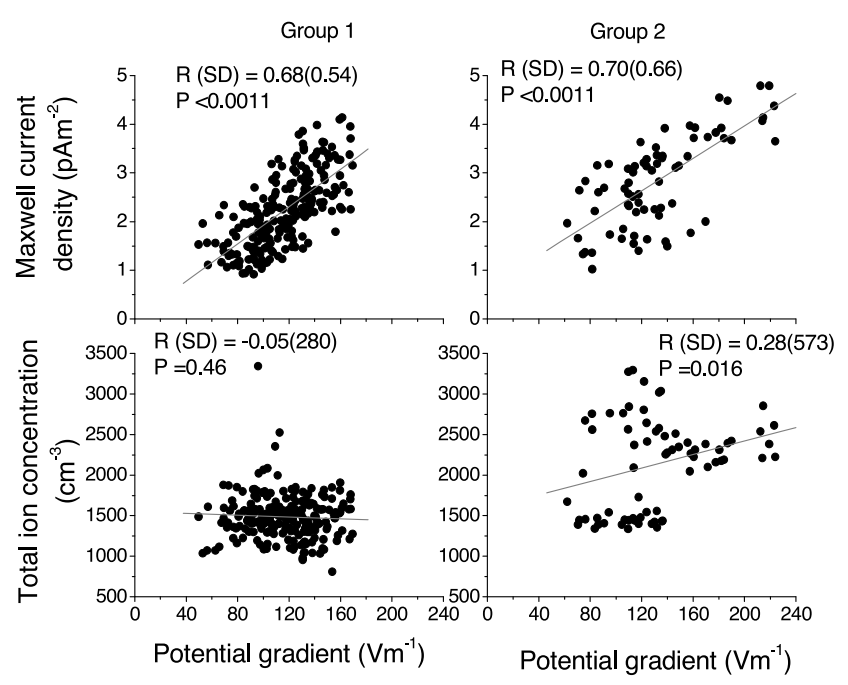

Fig. 5. The scattered plots of the Maxwell current density and the total ion concentration variations (mobility $>0.77-0.97 \times 10^{-4} \mathrm{~cm}^{2} \mathrm{~V}^{-1} \mathrm{~s}^{-1}$; diameter $<1.45-130 \mathrm{~nm}$ ) with the potential gradient for the two groups. The correlation coefficient (R) with the standard deviation (SD) and the physical significance level $(\mathrm{P})$ are given in each case.

dient and the Maxwell current at the Maitri station during 2001-2004, analyzed the data for 69 fair-weather days, and reported the diurnal variation to have a single periodic feature with a maximum at 1900 UT and a minimum at 0300 UT.

\subsection{Role of different sizes of ions}

Figure 5 shows the scattered plots of the total ion concentrations and the Maxwell current density against potential gradient. The Maxwell current density shows a good positive correlation with the correlation coefficient $\sim 0.70$ at the $<0.0001$ significance level. The total ion concentrations on group one days do not show any correlation, however, with the group two days, there is some positive correlation (correlation coefficient $\sim 0.28$ with a significance level of $\sim 0.016$ ). However, when the data from both groups are merged, the correlation coefficient becomes 0.29 with a significance level of $<0.0001$. Figure 6 shows scattered plots of ion concentrations (small, intermediate and large) with the air-earth current density. The correlation coefficients between the small ions and the air-Earth current density for the group one and group two days are 0.70 and 0.97 , respectively, with a very good significance level. Even the large ions have a positive good correlation (correlation coefficient $\sim 0.74$ for the both groups). The intermediate ions of group one days are negatively correlated (correlation coefficient $\sim-0.41, \mathrm{P}<0.0001$ ) whereas those of group two days show almost no correlation (correlation coefficient $=$ 0.06). When the two groups are merged, the ions of the small and large categories show a positive correlation (correlation coefficient 0.72 and 0.76 , respectively), whereas the intermediate ions show a negative correlation.

\section{Effect of Wind Speed and Surface Temperature on the Atmospheric Electricity Parameters}

Figure 7(a, b, c, d) shows the variations of ion concentrations, potential gradient, air-Earth current density and Maxwell current density with the surface temperature and

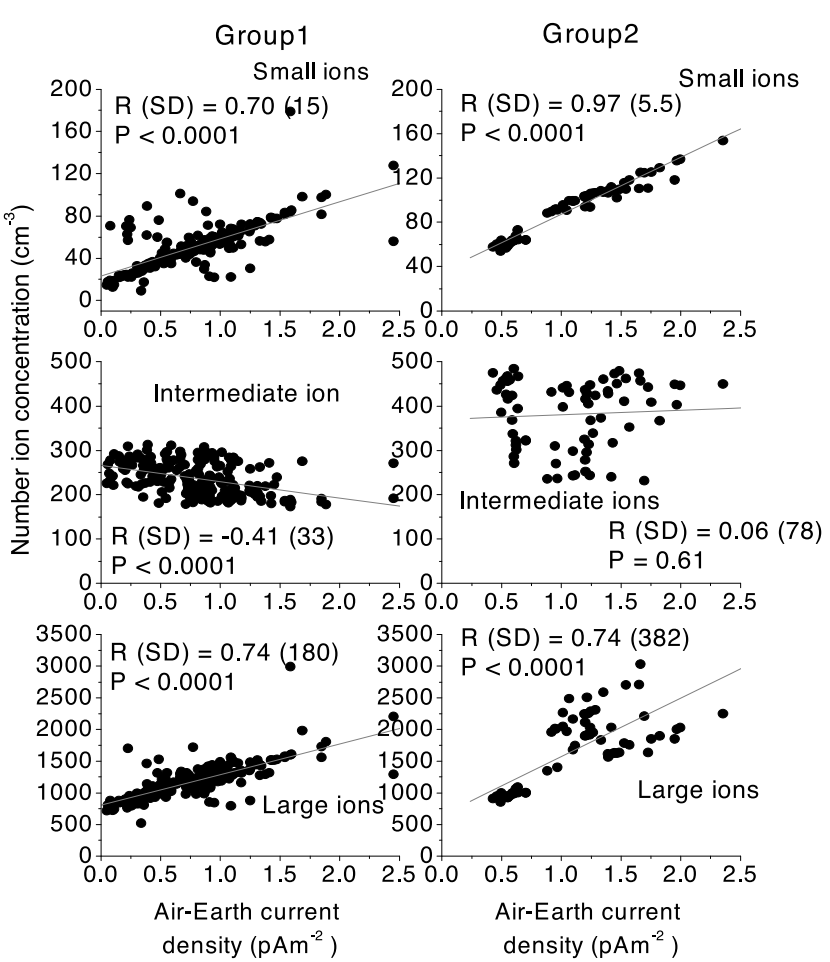

Fig. 6. Scattered plots of the different categories of ions (small, mobility $<0.77 \mathrm{~cm}^{2} \mathrm{~V}^{-1} \mathrm{~s}^{-1}$; diameter $<1.45 \mathrm{~nm}$; intermediate, mobility $1.21 \times 10^{-2}-0.77 \mathrm{~cm}^{2} \mathrm{~V}^{-1} \mathrm{~s}^{-1}$; diameter $1.45-12.68 \mathrm{~nm}$; and large, mobility $0.97 \times 10^{-4}-1.21 \times 10^{-2} \mathrm{~cm}^{2} \mathrm{~V}^{-1} \mathrm{~s}^{-1}$; diameter 12.68-130 $\mathrm{nm}$ ) for groups one and two with the air-Earth current density. The correlation coefficient $(\mathrm{R})$ with the standard deviation (SD) and physical significance level $(\mathrm{P})$ are given in each case.

wind speed. In group two, larger data are below the freezing level. With an increase of surface temperature, the potential gradient and the Maxwell current increases and the air-Earth current density decreases. The correlation coefficient and standard deviation, along with the significance level, is given in Table 2 and the results are summarized in Table 3. The concentration of small and large ions decreases with surface temperature, whereas that of the intermediate ions increases. The correlation coefficient is given in Table 2. We observe very good correlation in the case of the intermediate ions of group two. The results suggest that the contribution to the air-Earth current comes from the small and large ions. Based on simultaneous measurements of the ultrafine aerosol particles in the intermediate size range, Siingh et al. (2013a, b) showed the formation of new particles. The presence of a large number of ions during darkness at Maitri clearly suggests that a photolytic mechanism alone cannot explain the measurements. There may be some other mechanisms resulting in the formation of new ions which is operative at lower temperatures under dark conditions and is more effective at subfreezing temperatures. Based on aircraft and ground-based observations, Lee et al. (2008) reported new particle formation during night time without UV radiation under a low condensation sink. A higher concentration of aerosol precursors, and a lower temperature and surface areas, together can create an ideal condition for nucleation. The dependence of atmospheric electrical parameters on the wind speed is shown in Fig. 7(c,d). In the case of 

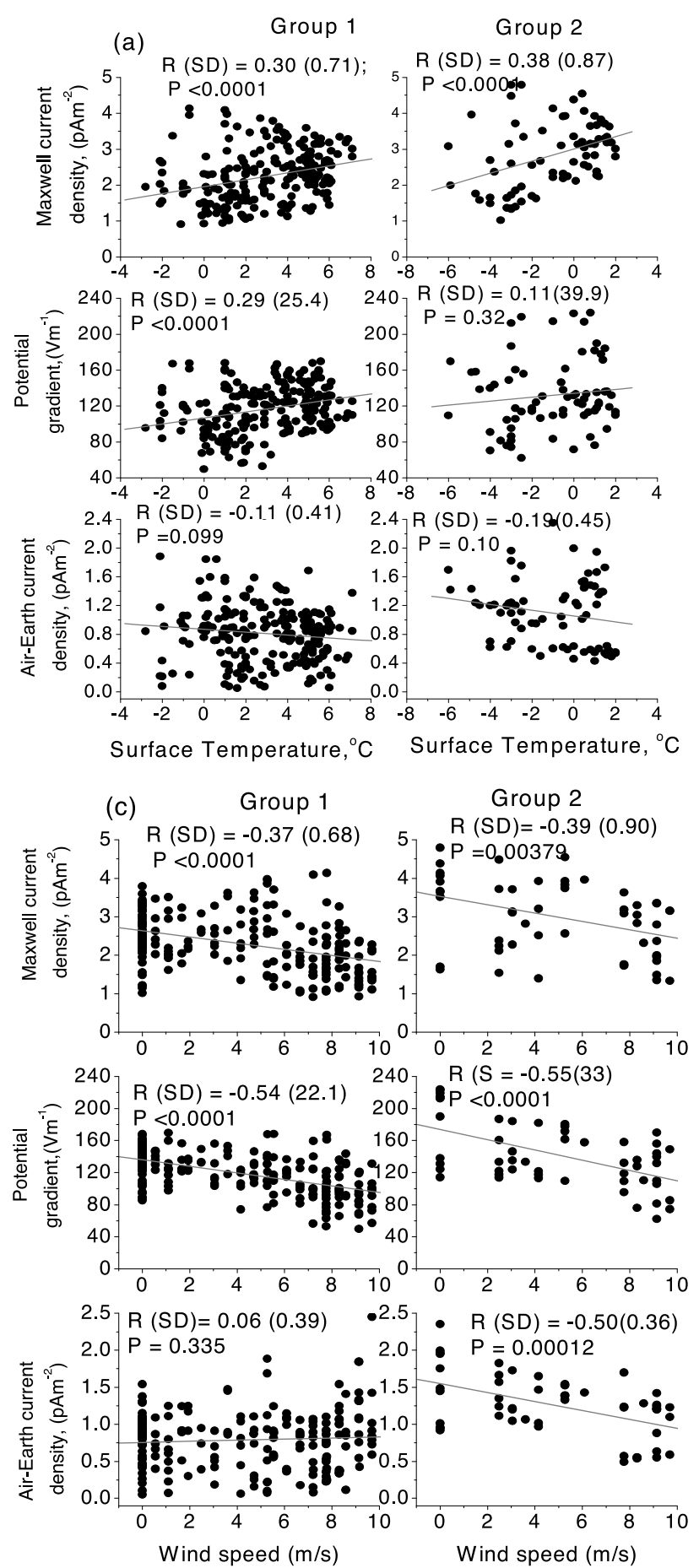
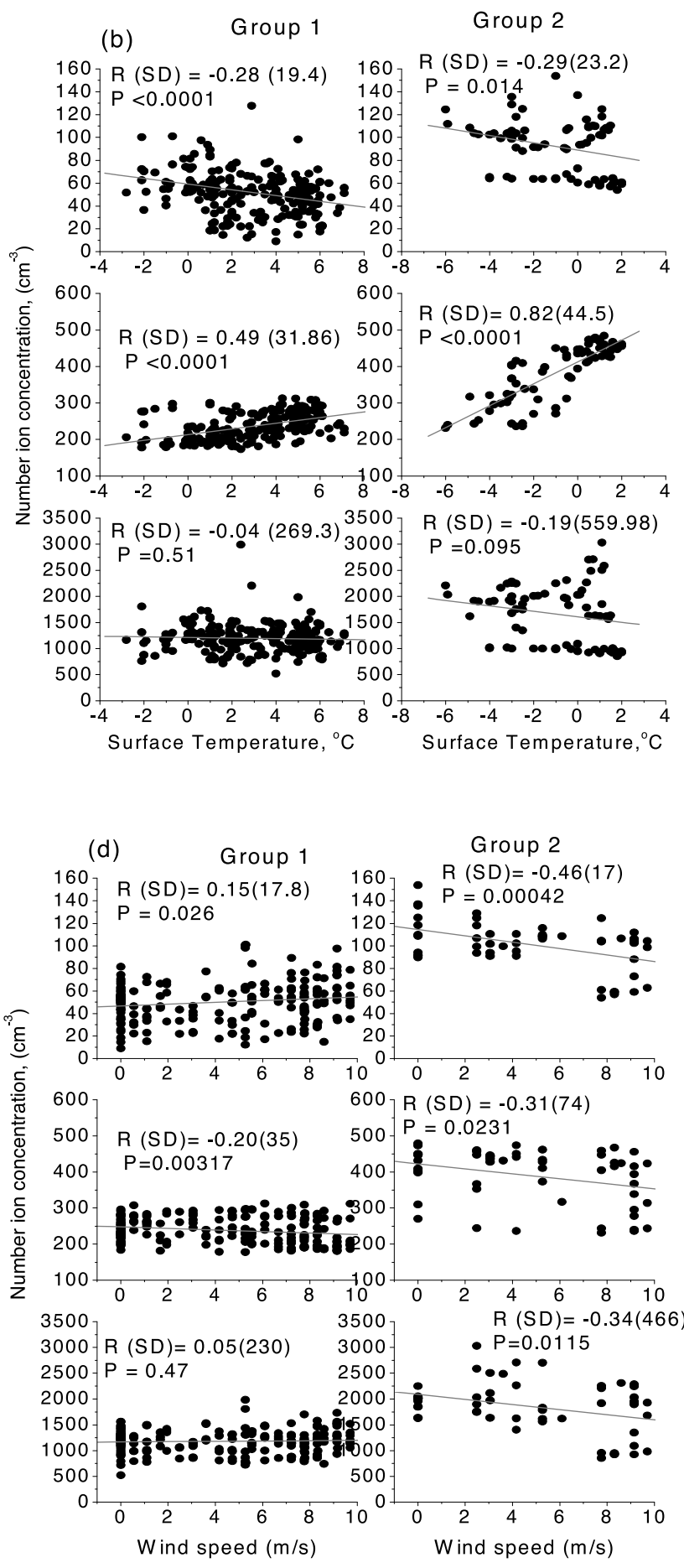

Fig. 7. Scattered plots of the Maxwell current density, potential gradient, air-Earth current density and the ion concentrations (small, intermediate and large ions) with the surface temperature ( $a$ and b) and (c and d) with the wind speed. The correlation coefficient (R) with the standard deviation (SD) and physical significance level $(\mathrm{P})$ are given in each level.

group two days, when the night-time temperature is below freezing level, all the studied parameters show a negative correlation with wind speeds (Table 2). For group one days, the Maxwell current density, potential gradient and intermediate ions have a negative correlation with wind speed, whereas the air-Earth current density and large ions do not show any correlation with wind speed. However, the small ions have some positive correlation. The relatively higher wind speed lifts negatively charged dust particles upward which may recombine with positive ions and convert them into neutral particles. This causes a decrease in the electrical parameters and, hence, the observation of a negative correlation. Dust particles may carry a negative charge because they are stripped off from the Earth's surface, which is at a negative potential with respect to the upper atmosphere (Kamra, 1972).

\section{Diurnal Variation of Conductivity}

The average atmospheric electrical conductivity calculated from small-ion concentrations is compared with the 
Table 2. Variation of correlation coefficient (R), standard deviation (SD) (significance level, P) of electrical parameters with the surface temperature and wind speed.

\begin{tabular}{lllll}
\hline Parameters & \multicolumn{2}{c}{ Surface Temperature } & \multicolumn{2}{c}{ Wind Speed } \\
& Group 1 & Group 2 & Group 1 & Group 2 \\
& R, SD & R, SD & R, SD & R, SD \\
& $(\mathrm{P})$ & $(\mathrm{P})$ & $(\mathrm{P})$ & $(\mathrm{P})$ \\
\hline Maxwell Current Density & $0.30,0.71$ & $0.38,0.87$ & $-0.37,0.68$ & $-0.39,0.90$ \\
& $(<0.0001)$ & $(<0.0001)$ & $(<0.0001)$ & $(0.00379)$ \\
Potential Gradient & $0.29,25.5$ & $0.11,0.39 .9$ & $-0.54,22.1$ & $-0.55,33$ \\
& $(<0.0001)$ & $(0.32)$ & $(<0.0001)$ & $(<0.0001)$ \\
Air-Earth Current Density & $-0.11,0.41$ & $-0.19,0.45$ & $0.06,0.39$ & $-0.50,0.36$ \\
& $(0.099)$ & $(0.10)$ & $(0.335)$ & $(0.00012)$ \\
Small-Ion Concentration & $-0.28,19.4$ & $-0.29,23.2$ & $0.15,17.8$ & $-0.46,17$ \\
Intermediate-Ion Concentration & $(<0.0001)$ & $(0.014)$ & $(0.026)$ & $(0.00042)$ \\
& $0.49,31.86$ & $0.82,44.5$ & $-0.20,35$ & $-0.31(74)$ \\
Large-Ion Concentration & $(<0.0001)$ & $(<0.0001)$ & $(0.00317)$ & $(0.0231)$ \\
& $-0.04,269.3$ & $-0.19,559.9$ & $0.05,230$ & $-0.34,466$ \\
\hline
\end{tabular}

Table 3. Diurnal variation and dependence on surface temperature and wind velocity of atmospheric electrical parameters.

\begin{tabular}{|c|c|c|c|}
\hline Parameters & Diurnal Variation & Surface Temperature & Wind Speed \\
\hline Maxwell Current Density & $\begin{array}{l}\text { Diurnal variation with a maximum } \\
\text { between } 1800 \text { and } 2000 \text { UT }\end{array}$ & Increases & Decreases \\
\hline Potential Gradient & $\begin{array}{l}\text { Diurnal variation with a maximum } \\
\text { between } 1800 \text { and } 2000 \text { UT }\end{array}$ & Increases & Decreases \\
\hline Air-Earth Current density & No diurnal variation & Slow decrease & $\begin{array}{l}\text { no effect (Group } 1 \\
\text { Decreases (Group } 2\end{array}$ \\
\hline Small-Ion Concentration & No diurnal variation & Decreases & $\begin{array}{l}\text { Increases (Group1) } \\
\text { Decreases (Group2) }\end{array}$ \\
\hline Intermediate-Ion Concentration & $\begin{array}{l}\text { Diurnal variation with a flat maximum } \\
\text { between } 800 \text { and } 1800 \mathrm{UT}\end{array}$ & Increases & Decreases \\
\hline Large-Ion Concentration & No diurnal variation & $\begin{array}{l}\text { Less dependence (Group1) } \\
\text { Decreases (Group2) }\end{array}$ & $\begin{array}{l}\text { No Dependence (Group 1) } \\
\text { Decreases (Group2) }\end{array}$ \\
\hline
\end{tabular}

conductivity derived from the air-Earth current density and potential gradient measurements (Fig. 8). In the same figure, we have also shown the diurnal variation of electrical conductivity measured by Panneerselvam et al. (2007a), during the 2001-2004 (summer) at Maitri, using a Gerdien's apparatus consisting of two identical cylindrical condensers of stainless steel having a common fan to suck the air. The signal from each condenser is amplified and fed through the Teflon insulated coaxial cables to a PC-based data acquisition system. Details are given in Panneerselvam et al. (2007a). The conductivity is almost constant within one $\sigma$ (standard deviation) and does not show any diurnal variation. The positive conductivity derived from the air-Earth current and electric field measurements and calculated from the small-ion concentration are almost equal and constant $\left(\sim 0.75 \times 10^{-14} \mathrm{~S} \mathrm{~m}^{-1}\right)$ after $0800 \mathrm{UT}$. Before 0800 UT, the conductivity derived from electric field measurements is larger than that calculated from small ion concentration, although within the error bar they are equal. As the conductivities are equal, we can argue that conductivity at Maitri could be dominantly controlled by small ions. The difference in the measured and calculated conductivity may restrict the application of Ohm's law. A local change in conductivity influences the electric field much more than the air-Earth current. Therefore, while using the electric field data in the study of atmospheric electricity, care must be taken while selecting the fair-weather days, and an attempt should be made to measure the conductivity, vertical current and electric field simultaneously.

\section{Comparison of the Maitri Electric Field to Global Values}

The electric fields measured at continent exhibit two types of variations: the single-oscillation type, such as the winter time fields at Vassijaure $\left(68.4^{\circ} \mathrm{N} ; 18.2^{\circ} \mathrm{E}\right)$ (Norinder, 1916), the Carnegie curve derived from measurements over oceans (Whipple and Scrase, 1936), the present work at Maitri $\left(70^{\circ} 45^{\prime} 52^{\prime \prime} \mathrm{S}, 11^{\circ} 44^{\prime} 03^{\prime \prime} \mathrm{E}\right)$, earlier measurements at Maitri (Panneerselvam et al., 2007a), and the winter time fields at Marsta $\left(59.9^{\circ} \mathrm{N}, 17.6^{\circ} \mathrm{E}\right)$ during $1993-1998$ (Israelsson and Tammet, 2001); and the double-oscillation type at Uppsaloa $\left(59.8^{\circ} \mathrm{N}, 17.6^{\circ} \mathrm{E}\right)$ during the summer (Norinder, 1917), and at Marsta during the summer. The Carnegie curve is considered to reflect the true nature of global variations because the local diurnal variation is strongly suppressed over the oceans (Israel, 1973; Willimas and Heckman, 1993). The diurnal variation of continental measurements typically follows the local time. How- 


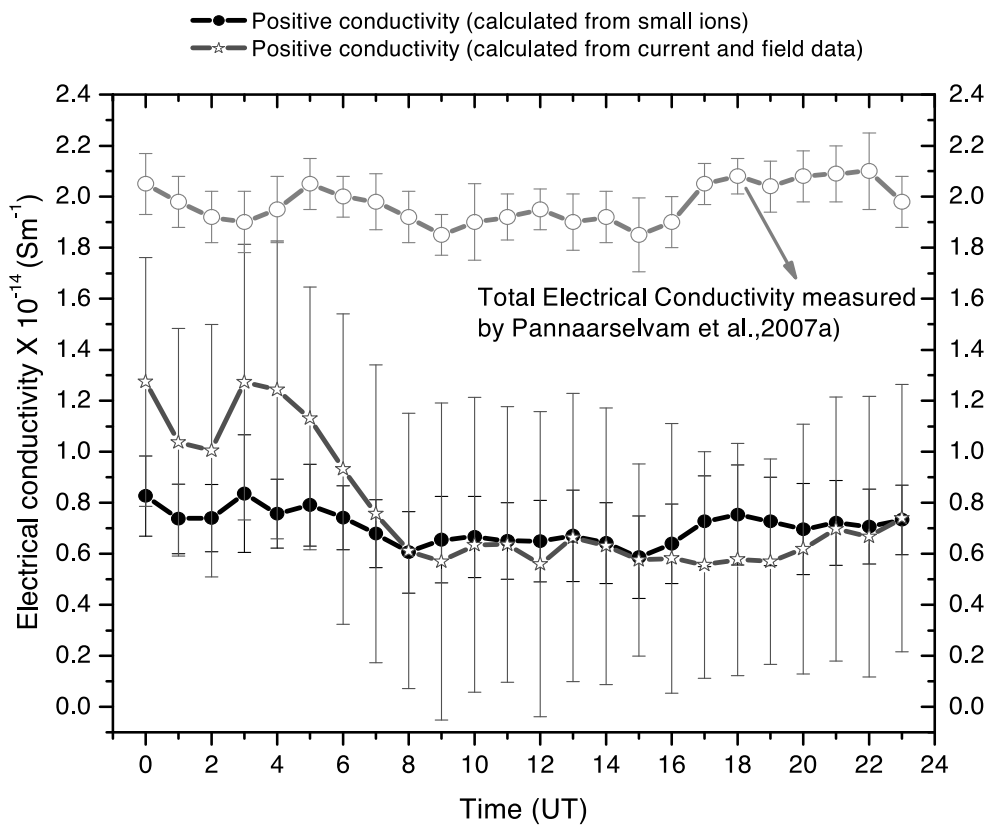

Fig. 8. Average diurnal variation of positive electrical conductivity calculated from small-ion concentration, total electrical conductivity (both positive and negative) measured at Maitri (Panneerselvam et al., 2007a), and positive electrical conductivity calculated from field and current data measured at Maitri.

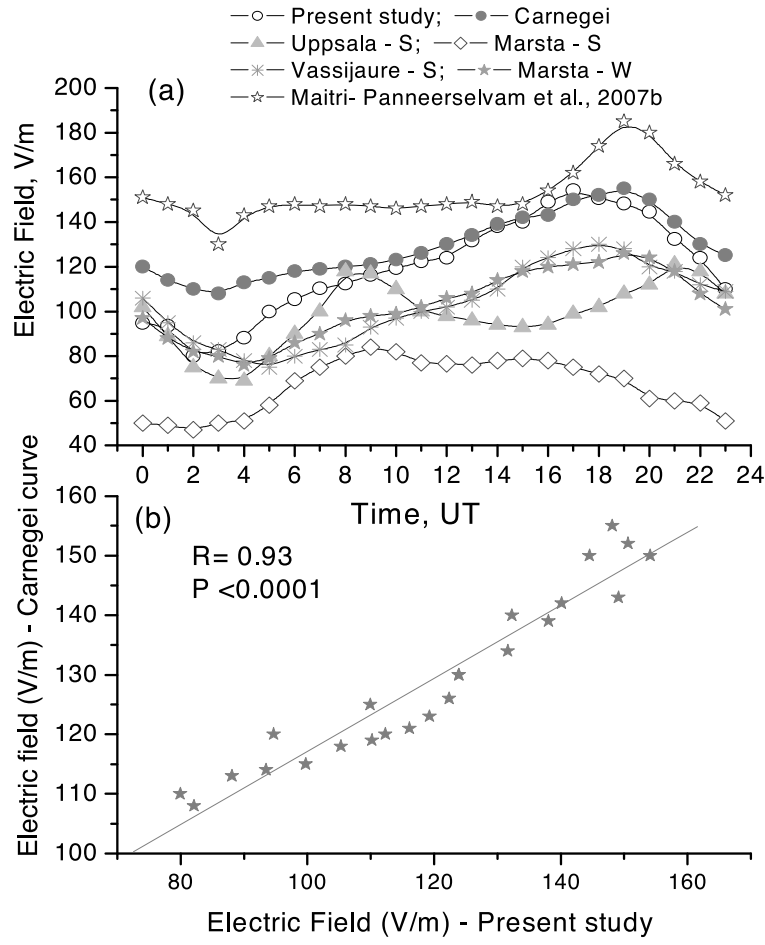

Fig. 9. (a) Comparison of diurnal variations of electric field measured at different places. (b) Scattered plots of electric field of Carnegie experiment with the present study ( $\mathrm{S}$ for summer, $\mathrm{W}$ for winter).

ever, Paramonov (1950) found that the averages over a large number of stations spread over the globe follow the global nature like the oceanic measurements.

For ready reference and comparative study, fields measured at different stations are shown in Fig. 9(a). The diurnal variation of the electric field at Marsta (during winter),
Vassijaure (during summer), and the present study (during summer) are very similar to the Carnegie curve, although the magnitude differs. The magnitudes cannot be compared as fields were measured at different locations, during different years and using different equipment having a different calibration/sensitivity. The electric field at Marsta during the winter represents the global nature because, during the winter, the temperature is low, the soil is frozen, and exhalation of radon is low which may lead to a low ion production and, hence, low conductivity. Even anthropogenic activity around the station is low, leading to a low concentration of aerosols and, hence, less ion-aerosol attachment and a higher value of conductivity. Furthermore, local atmospheric electric generators are active in the summer and inactive in the winter. These effects cause the winter measurements to be closer to the global variation as represented by the Carnegie curve. The values reported in the present study at Maitri are quite close to the Carnegie values from $0800 \mathrm{hrs}$ UT to $2400 \mathrm{hrs}$ UT, whereas during $0000-0800$ hrs UT our values are smaller than the Carnegie values. As the nature of the variation is identical to the Carnegie curve, the local effects seem to be quite small and the data can be considered to be less affected by the anthropogenic air pollution and the present measurements can be considered to describe the global variations. Panneerselvam et al. (2007a) reported the electric field during fair-weather conditions (average 124 days) for the period of 2001-2004 (summer observations). They found a single periodic variation with a minimum at 0300 UT and a maximum at 1900 UT which was similar to the Carnegie curve, however the magnitude of the electric field was greater than the Carnegie value. In the present observations, the minimum value is found at 0200 UT and the maximum value at 1700 UT.

Figure 9(b) presents the scattered plots of the electric fields reported in the Carnegie curve and the present study 
and there is a very good correlation ( $\sim 93 \%)$, which shows that the trend obtained by the Carnegie curve is mirrored in our observations also. The field magnitude cannot be compared because this depends on the environment of the observation site and the change in local meteorological parameters. Israelson and Tammet (2001) attempted to determine the contribution of local meteorological parameters to the changes in global measurements of the electric field using a reduction technique, which was found to be inadequate. Further studies in this direction are needed.

\section{Summary}

Measurements at the Indian station Maitri show similar diurnal variations in the Maxwell current and the electric field with a maximum between 1800 UT and 2000 UT, which are attributed to global lightning discharge activity. The small- and large-ion concentrations follow the air-earth current density diurnal variations, whereas the intermediate-ion concentration does not follow the air-Earth current density, but it shows a flat maxima between 0900 UT and 1700 UT. The enhancement in ion concentration correlates with the rise in daytime surface temperature and may be attributed to new particle formation. This flat maxima becomes more prominent in the case of group two days, when the night-time temperature goes below the freezing point and the day time temperature is less than $3^{\circ} \mathrm{C}$. The averaged data of group one days show a peak in the airEarth current at $0500 \mathrm{UT}$, which is not present in the data of the group two days. However, no such peak is observed in the electric field and Maxwell current density. Further study is required to understand the presence of the peak on the group one days and its disappearance on the colder fairweather days.

The total ion concentration does not show any correlation with the electric field; however, when the night-time temperature goes below freezing, there is a small positive correlation (correlation coefficient $=0.28$ ). The Maxwell current is well correlated (correlation coefficient $=0.68$ and $0.70)$ with the electric field in both groups. The small, and the large, ions are very well correlated with the air-Earth current density. However, the situation is quite different with the intermediate ions. In the case of the group one days, there is a negative correlation (correlation coefficient $=-0.41$ ) whereas there is no correlation in the case of group two days. Thus, most of the contribution to the airEarth current seems to come from the small and large ions.

The impact of wind velocity on the ion concentration, air-Earth current density, Maxwell current density and electric field varies. On group one days, the intermediate ions are barely negatively correlated (correlation coefficient $=$ -0.20 ) whereas the small ions show some positive correlation. The large ions do not show any meaningful correlation. On relatively colder days (group two), there is a negative correlation (correlation coefficient $\sim-0.31$ to -0.46 ) for all three categories of ions. The electric field, Maxwell current density and air-Earth current density decrease with the increase in wind speed, except that on group one days the air-Earth current density does not show any dependence.

On fair-weather days, the surface temperature varied either between $-3^{\circ} \mathrm{C}$ and $8^{\circ} \mathrm{C}$ or between $-7^{\circ} \mathrm{C}$ and $3^{\circ} \mathrm{C}$. The small-ion concentration in both cases showed a negative correlation with the surface temperature. The intermediateion concentration showed a good positive correlation. The large ions show a barely negative correlation on colder days and almost no correlation on the rest of the days. With the increase of surface temperature, the electric field and the Maxwell current density increase whereas the air-Earth current density decreases. Interestingly, it is found that the intermediate ions showed a relatively larger effect as compared with the small and the large ions.

Furthermore, the electric field measured at the Maitri station on the fair-weather days is compared with different available fair-weather measurements. The values presented in this paper and the diurnal variations are quite close to the Carnegie values, having a correlation coefficient of $\sim 0.93$ with a very good significance level. The measured values match between 0800 UT and 2200 UT, and outside this time our values are somewhat smaller. Based on the present study, we can safely conclude that the electric fields at the Maitri station, Antarctica, truly represent the global nature of the electric field. However, further study is recommended to find the effect of geomagnetic storms and other solar events on different atmospheric electrical parameters during both fair-weather days and disturbed days.

Acknowledgments. Devendraa Siingh (DS) gratefully acknowledges the National Centre for Antarctic and Ocean Research (NCAOR), Goa, India, for giving him an opportunity to participate in the 24th Indian Scientific Expedition to Antarctica (ISEA), and to the India Meteorological Department for providing the Meteorological data. Thanks are due to Dr. A. K. Kamra for the support extended during the expedition and Vimlesh Pant (research scholar) for his support during the period of observation. DS and VG are grateful to the Ministry of Earth Sciences, Govt. of India, New Delhi, also express their sincere gratitude to Professor B. N. Goswami, Director, Indian Institute of Tropical Meteorology, Pune, for his continuous encouragement and support. This work is partially supported under the collaboration programme of IITM, Pune and BHU Varanasi. We gratefully acknowledge the constructive remarks of the anonymous reviewers, which has improved the quality of the work.

\section{References}

Alderman, E. J. and E. R. Williams, Seasonal variation of the global electrical circuit, J. Geophys. Res., 101, 29679-29686, 1996.

Anderson, R. V., Measurement of worldwide diurnal atmospheric electricity variation, Mon. Wea. Rev., 95, 899-904, 1967.

Bering, E. A., A. A. Few, and J. R. Benbrook, The global electric circuit, Phys. Today, 51, 24-30, 1998.

Boyle, C. B., P. H. Reiff, and M. R. Hairston, Empirical polar cap potentials, J. Geophys. Res., 102, 111-125, 1997.

Burns, G. B., M. H. Hesse, S. K. Parcell, S. Malachowski, and K. D. Cole, The geoelectric field at Davis station, Antarctica, J. Atmos. Sol. Terr. Phys., 57, 1783-1797, 1995.

Byrne, G. J., J. R. Benbrook, E. A. Bering, G A. Few, A. A. Morris, W. J. Trabucco, and E. W. Paschal, Ground-based instrumentation for measurements of atmospheric conduction current and electric field at the South Pole, Geophys. Res. Lett., 98, 2611-2618, 1993.

Cobb, W. E., The atmospheric electric climate at Mauna Loa, J. Atmos. Sci., 25, 470-480, 1968.

Cobb, W. E., Atmospheric electric measurements at the South Pole, in Electrical Processes in Atmosphere, edited by H. Dolezalek and R. Reiter, pp. 161-167, Steinkopff, Darmstadt, Germany, 1977.

Covert, D. S., V. N. Kapustin, T. S. Bates, and P. K. Quinn, Physical properties of marine boundary layer aerosol particles of the mid-Pacific in relation to sources and meteorological transport, J. Geophys. Res., 101, 6919-6930, 1996.

Davison, B. et al., Dimethyl sulphide and its oxidation products in the 
atmosphere of the Atlantic and Southern oceans, Atmos. Environ., 30, 1895-1906, 1996.

Deshpande, C. G. and A. K. Kamra, Diurnal variations of the atmospheric electric field and conductivity at Maitri, Antarctica, J. Geophys. Res., 106, 14207-14218, 2001.

Fuellekrug, M., A. C. Fraser-smith, E. A. Bering, and A. A. Few, On the hourly contribution of global cloud-to-ground lightning activity to the atmospheric electric field in the Antarctic during December 1992, $J$. Atmos. Sol. Terr. Phys., 61, 745-750, 1999.

Israel, H., Atmospheric Electricity, vol. II, $350 \mathrm{pp}$., Israel program for scientific translation, Jerusalem, 1973.

Israelsson, S. and H. Tammet, Variation of fair weather atmospheric electricity at Marsta Observatory, Sweden, 1993-1998, J. Atmos. Sol. Terr. Phys., 63(16), 1693-1703, 2001.

Ito, T., Study of background aerosol in the Antarctic troposphere, J. Atmos. Chem., 3, 69-91, 1985.

Jeeva, K., C. Panneerselvam, K. U. Nair, C. Selvaraj, A. Dhar, B. M. Pathan, and S. Gurubaran, Global electric circuit parameters and their variability observed over Maitri, Antarctica, J. Geophys. Sco. India, 78, 199-210, 2011.

Kamra, A. K., Measurement of the electrical properties of dust storms, $J$. Geophys. Res., 77, 5856-5869, 1972.

Kamra, A. K., C. G. Deshpande, and V. Gopalakrishnan, Challenge to the assumption of the unitary diurnal variation of the atmospheric electric field based on observations in the Indian Ocean, Bay of Bengal and Arabian Sea, J. Geophys. Res., 99, 21043-21050, 1994.

Kamra, A. K., D. Siingh, and V. Pant, Scavenging of atmospheric ions and aerosols by drifting snow in Antarctica, Atmos. Res., 91, 215-218, 2009.

Kasemir, H., Atmospheric electric measurements in the Arctic and Antarctic, Pure Appl. Geophys., 100, 70-80, 1972.

Krider, E. P. and J. A. Musser, Maxwell currents under thunderstorms, $J$. Geophys. Res., 87, 11171-11176, 1982.

Lee, S.-H., L.-H. Young, D. R. Benson, T. Suni, M. Kulmala, H. Junninen, T. L. Campos, D. C. Rogers, and J. Jensen, Observations of nighttime new particle formation in the troposphere, J. Geophys. Res., 113, D10210, doi:10.1029/2007JD009351, 2008.

Markson, R., Airborne atmospheric electrical measurements of variation of ionospheric potential and electrical structure in the exchange layer over the ocean, in Electrical Processes in Atmosphere, edited by $\mathrm{H}$. Dolezalek and R. Reiter, pp. 450-459, Steinkopff, Darmstadt, Germany, 1977.

Mauchly, S. J., Diurnal variations of the potential gradient of atmospheric electricity, Terr. Magn. Atmos. Electr., 28, 61-81, 1923.

Minamoto, Y. and A. Kadokura, Extracting fair-weather data from atmospheric electric-field observations at Syowa Station, Antarctica. Polar Sci., 5, 313-318, 2011.

Morita, Y., The diurnal and latitudinal variation of electric field and electric conductivity in the atmosphere over the Pacific Ocean, J. Meteor. Soc. (Jpn.), 49, 56-58, 1971.

Nandy, D., A. Munoz-Jaramillo, and P. C. H. Martens, The unusual minimum of sunspot cycle 23 caused by meridional plasma flow variations, Nature, 472, 80-82, doi:10.1038/nature09786, 2011.

Norinder, H., Observations de l' electricité atmosphérique à Vassijaure, Kgl. Svenska Vetenskapsakad. Handlingar, 55(6), 1-60, 1916.

Norinder, H., Recherches sur le gradient du potential électrique de l'atmosphère à Upsala, Kgl. Svenska Vetenskapsakad. Handlingar, 58(4), 1-57, 1917.

O'Dowd, C. D., M. H. Smith, I. E. Consterdine, and J. A. Lowe, Marine aerosol, sea salt and the marine sulphur cycle: a short review, Atmos. Environ., 31, 73-80, 1997.

Panneerselvam, C., K. U. Nair, K. Jeeva, C. Selvaraj, S. Gurubaran, and R. Rajaram, A comparative study of atmospheric Maxwell current and electric field from a low latitude station Tirunelveli, Earth Planets Space, 55, 697-703, 2003

Panneerselvam, C., C. Selvaraj, K. Jeeva, K. U. Nair, C. P. Anlikumar, and S. Gurubaran, Fair-weather atmospheric electricity at Antarctica during local summer as observed from Indian station, Maitri, J. Earth System Sci., 116, 179-186, 2007a.

Panneerselvam, C., K. U. Nair, C. Selvaraj, K., Jeeva, C. P. Anlikumar, and S. Gurubaran, Diurnal variation of atmospheric Maxwell current over low-latitude continental station, Tirunelveli, India $\left(8.7^{\circ} \mathrm{N}, 77.8^{\circ} \mathrm{E}\right)$, Earth Planets Space, 59, 429-435, 2007b.

Pant, V., D. Siingh, and A. K. Kamra, Concentrations and size distributions of aerosol particles at Maitri during the passage of cyclonic storms revolving around the continent of Antarctica, J. Geophys. Res., 115, D17202, doi:10.1029/2009JD013481, 2010.
Papitashvili, V. O., F. J. Rich, M. A. Heinemann, and M. R. Hairston, Parameterization of the Defense Meteorological Satellite Program ionospheric electrostatic potentials by the interplanetary magnetic field strength and direction, J. Geophys. Res., 104, 177-184, doi:10.1029/1998JA900053,1999.

Paramonov, N. A., The unitary variation of the potential gradient of atmospheric electricity, Dolkady Akademii Nauk, 70, 37-38, 1950 (in Russian).

Park, C. G., Solar magnetic sector effects on the vertical atmospheric electric field at Vostok, Antarctica, Geophys. Res. Lett., 3(8), 475-478, 1976.

Reiter, R., Phenomena in Atmospheric and Environmental Electricity, Elsevier, Amsterdam, 1992.

Ruttenberg, S. and R. E. Holzer, Atmospheric electric measurements in Pacific Ocean, Geophysical Research Pap. 42, Air Force Cambridge Research Center, Bedford, Massachusetts, pp. 101-108, 1955.

Rycroft, M. J., S. Israelsson, and C. Price, The global atmospheric electric circuit, solar activity and climate change, J. Atmos. Sol. Terr. Phys., 62, 1563-1576, doi:10.1016/S1364-6826(00)00112-7, 2000.

Sheftel, V. M., A. K., Chernyshev, and S. P. Chernysheva, Air conductivity and atmospheric electric field as an indicator of anthropogenic atmospheric pollution, J. Geophys. Res., 99(D5), 10793-10795, doi:10.1029/94JD00287, 1994.

Siingh, D., R. P. Singh, A. K. Kamra, P. N. Gupta, R. Singh, V. Gopalakrishnan, and A. K. Singh, Review of electromagnetic coupling between the Earth's atmosphere and space environment, J. Atmos. Sol. Terr. Phys., 67, 637-658, 2005a.

Siingh, D., S. D. Pawar, V. Gopalkrishnan, and A. K. Kamra, Measurements of ion concentrations and conductivity over the Arabian Sea during the ARMEX, J. Geophys. Res., 110, D18207, doi: 10.1029/2005JD005765, 2005b.

Siingh, D., V. Gopalakrishnan, R. P. Singh, A. K. Kamra, S. Singh, V. Pant, R. Singh, and A .K. Singh, The atmospheric global electric circuit: an overview, Atmos. Res., 84, 91-110, doi:10.1016/j.atmosres.2006.05.005, 2007a.

Siingh, D., V. Pant, and A. K. Kamra, Measurements of positive ions and air-Earth current density at Maitri, Antarctica, J. Geophys. Res., 112, D13212, doi:10.1029/2006JD008101, 2007b.

Siingh, D., A. K. Singh, R. P. Patel, R. Singh, R. P. Singh, B. Vennadhari, and M. Mukherjee, Thunderstorm, lightning, sprites and magnetospheric whistler-mode waves, Surv. Geophys., 29(6), 499-551, 2008.

Siingh, D., R. P. Singh, A. K. Singh, M. N. KulkarnI, A. S. Gautam, and A. K. Singh, Solar activity, lightning and climate, Surv. Geophys., 32 , 659-703, doi:10.1007/s10712-011-9127-1, 2011a.

Siingh, D., V. Gopalakrishnan, A. S. Gautam, and R. P. Singh, Estimation of aerosol size distribution using $\mathrm{KL}$ model from the ion-mobility spectra, Int. J. Remote Sensing, 32, 6783-6798, doi: 10.1080/01431161.2010.512945, $2011 \mathrm{~b}$.

Siingh, D., D. M. Chate, and K. Ali, Time-elapsed evolution of aerosol size distributions by snow particles after the passage of blizzards over the Maitri (Antarctica), Int. J. Remote Sensing, 33, 962-978, doi:10.1080/01431161.2010.542206, 2012.

Siingh, D., A. S. Gautam, A. K. Kamra, and K. Komsaare, Nucleation events for the formation of charged aerosol particles at a tropical station-preliminary results, Atmos. Res., 132, 133-252, doi:10.1016/j.atmosres.2013.05.024, 2013a.

Siingh, D., V. Pant, and A. K. Kamra, Temperature-dependence of the positive intermediate ion concentration at Maitri, Antarctica, J. Atmos. Sol.-Terr. Phys., 104, 67-74, doi:10.1016/j.jastp.2013.08.11, 2013b.

Singh, D. K., R. P. Singh, and A. K. Kamra, The electrical environment of the Earth's atmosphere: A review, Space Sci. Rev., 113, 375-408, 2004.

Takagi, M., On the regional effect in the global atmospheric electric field, in Electrical Processes in Atmosphere, edited by H. Dolezalek and R. Reiter, pp. 477-481, Steinkopff, Darmstadt, Germany, 1977.

Troshichev, O. A., A. Frank-Kamenetsky, G. Burns, M. Fuellekrug, A. Rodger, and V. Morozov, The relationship between variations of the atmospheric electric field in the southern polar region and thunderstorm activity, Adv. Space Res., 34, 1801-1805, doi:10.1016/j.asr.2003.07.063, 2004.

Whipple, F. J. W. and F. J. Scrase, Point discharge in the electric field of the Earth, Geophys. Memoirs of London VII (68), 1-20, 1936.

Williams, E. R., Global circuit response to seasonal variations in global surface air temperature, Mon. Wea. Rev., 122, 1917-1929, 1994.

Williams, E. R. and S. J. Heckman, The local diurnal variation of cloud electrification and the global diurnal variation of negative charge on the Earth, J. Geophys. Res., 98(D3), 5221-5234, doi:10.1029/92JD02642, 
1993.

Williams, E. R. and E. Mareev, Recent progress on the global electrical circuit, Atmos. Res., doi:10.1016/j.atmosres.2013.05.015, 2013.

Wilson, C. T. R., Investigation on lightning discharges and on the electric field of thunderstorm, Phil. Trans. R. Soc. Lond. Ser. A, 221, 73-115, 1920.

Wilson, C. T. R., The electric field of a thunderstorm and some of its effects, Proc. R. Soc. Lond., 37, pp. 32D-37D, 1925.
Willett, J. C. and J. C. Bailey, Contact-potential and surface charge effects in atmospheric-electrical instrumentation, Naval Research Laboratory, Memorandum Report 5063, Washington, D.C. 1983.

D. Siingh (e-mail: devendraasiingh@tropmet.res.in), R. P. Singh, V. Gopalakrishnan, C. Selvaraj, and C. Panneerselvam 